\title{
Gastroesophageal reflux disease in pregnancy
}

\author{
Ramona Georgiana VARSA ${ }^{1}$, Anca Marina CIOBANU ${ }^{1,2}$, Brindusa Ana CIMPOCA-RAPTIS ${ }^{1}$, \\ Corina GICA ${ }^{1}$, Radu BOTEZATU ${ }^{1,2}$, Nicolae GICA $^{1,2}$, Gheorghe PELTECU ${ }^{1,2}$, \\ Anca Maria PANAITESCU ${ }^{1,2}$ \\ ${ }^{1}$ Filantropia Clinical Hospital, Bucharest, Romania \\ 2"Carol Davila" University of Medicine and Farmacy, Bucharest, Romania
}

\begin{abstract}
Gastroesophageal reflux disease (GERD) is one of the most common gastrointestinal (GI) disorders and, despite the fact that it is a benign condition, it may seriously affect the quality of life of women during pregnancy. The most commonly symptoms seen of GERD are heartburn and reguritation and the cause is probably an association between the decreased pressure in lower esophageal sphincter (LES), influenced by the high concentrations of estrogen and progesterone, and the increased intra-abdominal pressure.

Contrary to non-pregnant patients, the management of GERD during pregnancy is based on a step-up algorithm, beginning with lifestyle modifications and dietary changes. If symptoms persist, or in case of complicated reflux disease, antacids or sucralfate are considered the first-line therapy, followed by the histamine-2-receptor antagonists and proton pump inhibitors.

The purpose of this article is to make a review of the medical literature concerning the symptoms, pathophysiology, diagnosis, and management of GERD in pregnancy.

For this purpose, a scientific research in databases such as Medline, PubMed, Elsevier, The Lancet was conducted
\end{abstract}

Keywords: gastroesophageal reflux, pregnancy

\section{DEFINITION AND EPIDEMIOLOGY}

Gastroesophageal reflux disease is defined by the American College of Gastroenterology, as "symptoms or complications resulting from the reflux of gastric contents into the esophagus or beyond, into the oral cavity (including larynx) or lung" [1].

It is one of the most common gastrointestinal (GI) disorders affecting women during pregnancy and can be seen in $40 \%$ to $85 \%$ of pregnant women [2].

Commonly, GERD starts at the end of the first trimester and worsen progressively in the next months but tends to disappear soon after delivery [3].

Despite the fact that it is a benign condition, without implications in the development of the fetus, it may greatly affect the quality of women's life during gestational period.

\section{RISK FACTORS AND PATHOPHYSIOLOGY}

The pathophysiology of GERD in pregnancy is complex. The causes are probably, a mix of mechanical and hormonal mechanisms, combined with alterations in gastric motility and other precipitating factors $[4,5]$.

According to a British study including 607 pregnant women, the risk factors for heartburn in pregnancy are preexisting heartburn, multiparty and gestational age $[3,7]$. The study have not shown an association between pre-pregnancy body mass index, race or weight gain during pregnancy and the onset of this condition $[3,7]$. Surprisingly, older age of the pregnant women may have a protective effect $[3,7]$. 
The mostly incriminated factor for GERD is a decrease in the LES pressure due to a progressive rise in circulating estrogen and progesterone [5].

Many studies have shown that LOS pressure decreases throughout the evolution of pregnancy [2].

An ancient study conducted by Van Thiel et al. [8] showed that resting LES pressure is lower than normal all along the pregnancy, with the peak at 36 weeks gestation. This decrease in sphincter pressure was accompanied by specific symptoms with subsequent return to normal pressure after delivery. However, the study conducted by Fisher et al. $[9,10]$, did not find a significant difference in LES pressure before and after therapeutic abortion during the first 20 weeks of pregnancy. But they did find that the physiologic adaptive sphincter responses to pharmacological and hormonal stimuli were altered. Consecutively, this suggests that some physiological alterations take place in early stages of pregnancy, followed by an ulterior significant decrease in LES pressure.

Both animal and human studies [11], concluded that the high level of progesterone during gestation mediates the smooth muscle relaxation of LES. Although the action of progesterone has been emphasized, the estrogen is an essential primer for this change to occur. Schulze et al. [12], using an animal model of opossums, showed in the 1970s, that administration of female sex steroids inducing a hormonal pseudo-pregnancy state, ended in lowering the pressure of LES. Subsequently, others found that progesterone in combination with ethinyl-estradiol decreased LOS pressure significantly [13]. Fisher et al. [9] also reported that the association of $17-\beta$-estradiol and progesterone profoundly decreased the pressure of LES. In addition, in the postpartum stage, the LES pressure is noted to rise back to pre-pregnancy values as hormone levels decrease drastically $[2,8]$.

Overall, these studies indicate the important roles for both progesterone and estrogen in lowering LES pressure, and suggest that their combined actions significantly contribute to this effect.

Hormonally induced alterations in gastro-intestinal (GI) motility, have also been involved. Pregnancy related hormones are thought to affect the function of the enteric nervous system and muscles that leads to a decrease in GI motility, which may promote GERD [2].

Many researchers have hypothesized that increasing intra-abdominal pressure caused by the enlarging gravid uterus may contribute to the symptoms of GERD. However, subsequent studies did not find enough proves to support this hypothesis. Additionally, because heartburn is typically reported early in pregnan$c y$, it is less likely that increased intra-abdominal pressure plays primary role [2].

And last but not least, the precipitating factors that may trigger the symptoms include ingestion of certain foods like mints, chocolate, caffeinated beverages, spicy or fatty food, eating soon before bedtime, consumption of alcohol and tobacco and also the administration of medications that decrease lower esophageal sphincter (LES) pressure [2]. Some medications that can decrease the pressure of the LES include calcium channel antagonists, anticholinergics, antipsychotic agents, antidepressants agents and theophylline [2].

\section{SYMPTOMS AND EVALUATION}

First symptoms of heartburn were reported in the first trimester in $50 \%$ of cases, in the second trimester in $20-40 \%$ of cases and in the last trimester of pregnancy in $10 \%$ of cases [6].

The clinical manifestation of GERD in pregnancy is similar to that in non-pregnant patients.

Besides the cardinal symptoms of heartburn and regurgitation, patients often complain of nausea, vomiting, epigastric pain, anorexia, dysphagia, water brash [2]. Atypical symptoms such as cough, dysphagia, globus sensation, laryngitis, hoarseness, sinusitis, chronic dry cough, dental erosions, recurrent aspiration, non-atopic asthma and non-cardiac chest pain, or bleeding may also occur [2].

The diagnosis of GERD can effectively be made only on symptoms alone. A careful anamnesis should be obtained, focused on current symptoms and any other previous dyspeptic or reflux-type disorder. In rare cases, invasive procedures such as $\mathrm{pH}$ probes and manometry, are needed, although there is no contraindication for their use during pregnancy [14]. Barium X-ray examination should be avoided because of the exposure of the fetus to radiation. In case of persistent symptomatology or complications such as dysphagia, hemorrhage, anemia and weight loss, upper gastrointestinal endoscopy may be indicated [2].

\section{MANAGEMENT}

The first-line therapy for gastroesophageal reflux disease in pregnancy is represented by the conservative measures such as life-style modifications and avoiding dietary triggers that may exacerbate symptoms [15]. The main life-style changes include eating smaller meals, elevating the head of the bed, not eating late at night, lying on the left side, limiting fluid intake with meals and increasing physical activity [15]. Avoiding the use of alcohol, tobacco, drugs that can lower LES pressure, certain foods such as chocolate, mints, fatty and spicy food, and certain beverages (coffee, citrus juices, tomato and carbonated products) also helps relieving the symptoms and are strongly recommended [15]. Following this advice, mild to moderate symptoms can usually be controlled [15].

When symptoms persist despite of conservative therapy, pharmacologic management may be taken 
into consideration. Unfortunately, many of the medications used to treat GERD in pregnancy have not been tested in randomized clinical trials in the pregnant population. As consequence, recommendations for medical therapy come from expert opinion, case reports and retrospective cohort studies (Table 1) [2,3]. In general, pharmacologic agents that are not absolutely required should be avoided 31 to 71 days from the last menstrual period because this is the most critical time of organogenesis [2,3].

TABLE 1. Medical treatment of GERD in pregnancy $[8,13,14]$

\begin{tabular}{|c|c|}
\hline \multicolumn{2}{|l|}{ ANTACIDS } \\
\hline $\begin{array}{l}\text { Aluminum, Calcium and } \\
\text { Magnesium containing } \\
\text { antacids }\end{array}$ & $\begin{array}{l}\text { Low risk in pregnancy; Minimal } \\
\text { absorption }\end{array}$ \\
\hline Magnesium trisilicates & $\begin{array}{l}\text { Avoid high-dose or long-term } \\
\text { treatment }\end{array}$ \\
\hline Sodium bicarbonate & $\begin{array}{l}\text { Not safe in pregnancy. Risk of } \\
\text { metabolic alkalosis and fluid } \\
\text { overload }\end{array}$ \\
\hline \multicolumn{2}{|l|}{ MUCOSAL PROTECTANTS } \\
\hline Sucralfate & $\begin{array}{l}\text { Low risk in pregnancy. Minimal } \\
\text { absorption }\end{array}$ \\
\hline \multicolumn{2}{|c|}{ H2 RECEPTORS ANTAGONISTS } \\
\hline Cimetidine & $\begin{array}{l}\text { Acceptable for use in pregnancy. } \\
\text { Antiandrogenic effects in adults }\end{array}$ \\
\hline Nizatidine & Not safe \\
\hline Famotidine & Low risk in pregnancy \\
\hline Ranitidine & $\begin{array}{l}\text { Low risk. Efficacity proved in } \\
\text { pregnancy }\end{array}$ \\
\hline \multicolumn{2}{|l|}{ PPIs } \\
\hline Dexlansoprazole & Safe in pregnancy, limited data \\
\hline Esomeprazole & Safe in pregnancy, limited data \\
\hline Lansoprazole & Safe in pregnancy, limited data \\
\hline Omeprazole & $\begin{array}{l}\text { Fetal and embryonic toxicity in } \\
\text { animals. Controversial data in } \\
\text { humans. Acceptable for use }\end{array}$ \\
\hline Pantoprazole & Safe in pregnancy, limited data \\
\hline Rabeprazole & Safe in pregnancy, limited data \\
\hline \multicolumn{2}{|l|}{ Dopamine antagonist } \\
\hline Metoclopramide & $\begin{array}{l}\text { Safe in pregnancy; limited human } \\
\text { data in pregnancy }\end{array}$ \\
\hline
\end{tabular}

Antacids are first line medical therapy because they are considered non-systemic drug therapy [4]. Moreover, they are often preferred by patients, because they are fast acting and effective at providing quick symptomatic relief. Those containing magnesium, calcium and aluminum, are considered safe in pregnancy at the usual doses $[2,3]$. However, antacids containing magnesium trisilicate, have been associated with respiratory distress, cardiovascular impairment, nephrolithiasis and hypotonia, when used at high doses for prolonged periods of time [2]. And last but not least, compounds containing sodium bicarbonate should be avoided because they are likely to precipitate metabolic alkalosis and fluid overload in both fetus and mother [4].

Sucralfate, another local acting agent, in dose of 1 gram $\times 3$ times/day, has been shown more effective in inducing symptomatic remission than lifestyle management alone, according to a randomized controlled trial during pregnancy [2-4]. No adverse maternal or fetal events were reported. In animal studies, sucralfate has no impact on fertility and has not teratogenic effect when taken in doses up to 50 times the recommeded human dose [2-4].

Histamine type 2 receptor antagonists (H2RAs) are often next-line therapy. Both ranitidine and cimetidine have been used in pregnancy for more than 30 years and have excellent safety profiles. Ranitidine has been specifically studied in pregnancy and has proved efficacy over conservative management and antacids. Although cimetidine has weak antiandrogenic effect in animals and has been associated with gynecomastia in adult men, there are no reports of sexual malformations among the infants exposed to cimetidine or other H2RAs [2,3].

In general, proton pump inhibitors (PPIs) are the most effective medical therapy for both controlling the symptoms and esophageal mucosa repair in GERD [3]. Similarly, in pregnancy, studies have shown that PPIs are more effective than other pharmacological therapy [2].

Omeprazole was the first PPI developed for clinical use. It was classified as dangerous for pregnancy because of dose-related fetal mortality in pregnant animals. Subsequent human studies have not shown a teratogenic effect, but the FDA classification has not changed [3]. For the rest of the PPIs their use in pregnancy is reserved for those cases involving complications of GERD or symptoms that do not respond to other therapies. In these cases, lansoprazole is often the chosen agent because it has the most safety data [4]. Animal studies using up to 40 times the recommended human dose of lansoprazole were performed and have not showed fetal toxicity [2].

Metoclopramide, a promotility agent, is primarily used in the treatment of pregnancy associated nausea and vomiting. Furthermore, it can also improve the symptoms of GERD by promoting gastric emptying, improving acid clearance, and increasing LES pressure. No congenital malformations or fetal toxicities have been associated with the use of metoclopramide in pregnancy $[2,3]$.

\section{CONCLUSIONS}

Currently, there is still much controversy surrounding the pathophysiology and treatment of GERD in 
pregnancy and the post-partum prognostic. Uniformity in strategies for GERD therapy is desirable to align conservative and medical strategies.

Proton pump inhibitors may be safely used in pregnancy because studies shows no increased fetal risks for major malformations.
Despite the fact that it is a benign condition, GERD may seriously affect the quality of life of women during pregnancy.
Conflict of interest: none declared Financial support: none declared

\section{REFERENCES}

1. Katz PO, Gerson LB, Vela MF. Guidelines for the diagnosis and management of gastroesophageal reflux disease. Am J Gastroenterol. 2013 Mar;108(3):308-28.

2. Ali RA, Egan LJ. Gastroesophageal reflux disease in pregnancy. Best Pract Res Clin Gastroenterol. 2007;21(5):793-806.

3. Richter JE. Review article: the management of heartburn in pregnancy. Aliment Pharmacol Ther. 2005 Nov 1;22(9):749-57.

4. Richter JE. Heartburn, nausea, and vomiting during pregnancy. In: Pregnancy in gastrointestinal disorders. Bethesda (MD): ACG Monograph American College of Physicians; 2007:18-25. Available at: https:// www.acg.gi.org.

5. Richter JE. Gastroesophageal reflux disease during pregnancy. Gastroenterol Clin North Am. 2003 Mar;32(1):235-61.

6. de Castro L P. Reflux esophagitis as the cause of heartburn in pregnancy. $A m \mathrm{~J}$ Obstet Gynecol. 1967 May 1;98(1):1-10.
7. Marrero JM, Goggin PM, de Caestecker JS, Pearce JM, Maxwell JD. Determinants of pregnancy heartburn. Br J Obstet Gynaecol. 1992 Sep;99(9):731-4

8. Van Thiel DH, Gavaler JS, Joshi SN, Sara RK, Stremple J. Heartburn of pregnancy. Gastroenterology. 1977 Apr;72(4 Pt 1):666-8.

9. Fisher RS, Roberts GS, Grabowski CJ, Cohen S. Inhibition of lower esophageal sphincter circular muscle by female sex hormones. Am J Physiol. 1978 Mar;234(3):E243-7.

10. Fisher RS, Roberts GS, Grabowski CJ, Cohen S. Altered lower esophageal sphincter function during early pregnancy. Gastroenterology. 1978 Jun;74(6):1233-7.

11. Broussard CN, Richter JE. Treating gastro-oesophageal reflux disease during pregnancy and lactation: what are the safest therapy options? Drug Saf. 1998 Oct;19(4):325-37.
12. Schulze K, Christensen J. Lower sphincter of the opossum esophagus in pseudopregnancy. Gastroenterology. 1977 Nov;73(5):1082-5.

13. Van Thiel DH, Gavaler JS, Stremple J. Lower esophageal sphincter pressure in women using sequential oral contraceptives. Gastroenterology. 1976 Aug;71(2):232-4.

14. Al-Amri SM. Twenty-four hour pH monitoring during pregnancy and at postpartum: a preliminary study. Eur J Obstet Gynecol Reprod Biol. 2002 May 10;102(2):127-30.

15. Thélin CS, Richter JE. Review article: the management of heartburn during pregnancy and lactation. Aliment Pharmacol Ther. 2020;51(4):421-34. 